Article

\title{
Quantitative Assessment and Visualisation of the Wood and Poly(Lactic Acid) Interface in Sandwich Laminate Composites
}

\author{
Warren Grigsby ${ }^{1, *(\mathbb{D}}$, Victor Gager ${ }^{2}$, Kimberly Recabar ${ }^{3}$, Andreas Krause ${ }^{4} \mathbb{D}$, Marc Gaugler ${ }^{1}$ \\ and Jan Luedtke 5 \\ 1 Manufacturing and Bioproducts, Scion, Rotorua 3010, New Zealand; marc.gaugler@scionresearch.com \\ 2 Department of Biocomposites, University of South Brittany, Lorient CEDEX 56321, France; \\ victor.gager@yahoo.fr \\ 3 School of Engineering, University of Waikato, Hamilton 3240, New Zealand; kim_24@windowslive.com \\ 4 Department of Biology, University of Hamburg, 21031 Hamburg-Bergedorf, Germany; \\ andreas.krause@uni-hamburg.de \\ 5 Thünen Institute of Wood Research, 21031 Hamburg, Germany; jan.luedtke@thuenen.de \\ * Correspondence: warren.grigsby@scionresearch.com
}

Received: 21 December 2018; Accepted: 30 January 2019; Published: 11 February 2019

\begin{abstract}
Fluorescence microscopy was applied to understand adhesion interfaces developed within laminated composite sandwiches formed between poly(lactic acid) (PLA) and wood veneers. Composites formed with maple veneer had greater tensile bond strength when manufactured at $200{ }^{\circ} \mathrm{C}\left(10.4 \mathrm{~N} / \mathrm{mm}^{2}\right)$ compared to formation at $140{ }^{\circ} \mathrm{C}\left(8.7 \mathrm{~N} / \mathrm{mm}^{2}\right)$, while significantly lower bond strength was achieved using spruce veneers, at 5.2 and $3.5 \mathrm{~N} / \mathrm{mm}^{2}$, respectively. Qualitative and quantitative confocal microscopy assessments revealed differing bondline thicknesses and PLA ingress within the wood ultrastructure. Forming maple veneer composites at $200{ }^{\circ} \mathrm{C}$ promoted greater PLA mobility away from the bondline to reinforce the wood-PLA interface and deliver associated greater composite bond strength. The addition of $25 \%$ wood fibre to PLA led to fibre alignment and overlap within bondlines contributing to relatively thicker, heterogeneous bondlines. Study outcomes show that the composite processing temperature impacts the adhesion interface and composite performance and will have broad application over veneer overlays, laminates and wood plastic composites (WPCs) using wood, particles or fibres with PLA.
\end{abstract}

Keywords: polylactic acid; wood plastic composites; laminates; adhesion; fluorescence microscopy

\section{Introduction}

Composite materials comprising natural fibres with thermoplastic matrixes are increasingly used across many sectors due to their formability, light weight, and design attributes [1]. It is common for wood plastic composites (WPCs) comprising wood-fibre-reinforced or -filled materials to be processed by compounding, extrusion, and injection and compression moulding for a range of product applications [2]. In addition to wood or other natural fibres, these composite materials can also contain renewable or sustainable matrixes such as poly(lactic acid) (PLA), a biodegradable polyester. As a replacement for the polyolefin plastics typically used in composites, such materials also offer additional economic and environmental advantages with respect to their end of life [3,4]. Poly(lactic acid) has been broadly considered for a range of applications including plastic components, films, packaging and paperboard products [3-5]. This includes PLA being evaluated in WPC materials for a range of applications [6]. Recently, the use of PLA in WPC materials has also been adapted to wood veneer to understand the adhesion developed at the wood-plastic interface $[7,8]$. In this 
wood laminate form, significant adhesion can be developed between the wood substrate and PLA on composite consolidation. This adhesion is developed over a range of scales from molecular- to macro-scale [8]. Initial evaluations of composite sandwiches formed with differing grades of PLA polymer and wood veneer species found a dependency between composite formation and performance with temperature [7]. However, it was also revealed at the micro-scale that the PLA bondline thickness between veneer surfaces within laminates may also dictate composite performance. Therefore, to develop the processing and performance of these promising composites, further understanding of the PLA adhesion, interactions and interphase at a wood cellular level is required.

In order to further develop a fundamental understanding of the PLA adhesion interface at a wood cellular level, further investigative analysis is required. A range of techniques are available to determine interfacial properties and behaviours at a wood ultrastructure level and include X-ray fluorescence microscopy, nanoindentation, scanning thermal microscopy and UV microscopy [9]. In the case of the latter, UV microscopy coupled with fluorescently tagged polyesters was initially applied to PLA-based WPCs to visualise interactions of PLA with wood fibre at microscale [10]. However, direct application of this methodology to composite sandwiches at a wood cellular level requires more investigation due to the challenges of distinguishing the PLA fluorescent chromophore from natural fibre components [7,11]. In the current paper a fluorescence microscopy methodology is further developed to quantify PLA polymer bondlines and interfacial adhesion developed between PLA and different wood species. By using two differing composite processing temperatures to alter PLA properties such as polymer flow and mobility, PLA migration into the ultrastructure of different wood species is characterised and compared with the composite performance. The outcomes of this study can be translated to the formation and integrity of wood interfaces with PLA or other polymers in a range of different WPCs, natural fibres and plastics applications.

\section{Materials and Methods}

Sycamore maple (Acer pseudoplatanus, hardwood) and spruce (Picea abies, softwood) sliced veneers $\left(0.6 \mathrm{~mm}\right.$ thickness) were used as wood substrates. Veneer specimens $\left(100 \times 20 \mathrm{~mm}^{2}\right)$ were cut from veneer sheets and conditioned at $20{ }^{\circ} \mathrm{C} / 65 \%$ relative humidity prior to sandwich composite formation. The amorphous grade of poly(lactic acid) (PLA) polymer was Ingeo 4060D and sourced from NatureWorks (Blair, NE, USA). This PLA was dried for $12 \mathrm{~h}$ under vacuum prior to any processing. Acriflavine, as acriflavine neutral chloride was obtained from Acros Organics (distributed by Thermo Fisher Scientific New Zealand Ltd.) and used as received. The wood fibres were generated by mechanically pulping Pinus radiata (softwood) chips using medium-density fibreboard processing conditions. These fibres were flash dried to $<12 \%$ moisture content $(\mathrm{mc})$ at the time of production and further dried $(<8 \% \mathrm{mc})$ immediately prior to compounding with PLA.

\subsection{Fluorescence Chromophore Label Grafting to PLA}

Using a modified methodology [10], PLA polymer was first dissolved in chloroform in a round-bottom flask. This flask was immersed in an oil bath and heated at $60-70{ }^{\circ} \mathrm{C}$ while maintaining stirring. In a separate flask, acriflavine (nominally $0.1 \% w / w$ on PLA) was dissolved in water and then neutralised to ca. $\mathrm{pH} 8$ with $1 \mathrm{M}$ sodium hydroxide. The aqueous solution was poured into the chloroform solution to form a heterogeneous reaction mixture. Heating of this reaction mixture was continued at $60-70^{\circ} \mathrm{C}$ under reflux for $17 \mathrm{~h}$. After cooling, the solution was separated by centrifuging and washing the chloroform phase with water. Water washing was continued until the washings were deemed colourless. The residual PLA/chloroform solution was then poured onto an aluminium tray and allowed to evaporate at ambient temperature for at least $24 \mathrm{~h}$. After evaporating, the fluorescently labelled PLA was recovered and further dried under vacuum at $45^{\circ} \mathrm{C}$ for $24 \mathrm{~h}$ to produce an estimated $0.07 \%$ acriflavine loading on PLA as a PLA master batch (Supplementary Materials). 


\subsection{Labelled PLA Compounding and Sheet (Foil) Preparation}

A Haake Rheomix Rheomex 600 OS mixer equipped with Roller Rotors from Thermo Scientific (Germany) was employed to process the fluorescence-labelled PLA master batch with varying quantities of pure PLA. Mixing was performed at $170{ }^{\circ} \mathrm{C}$ for $1 \mathrm{~min}$ to obtain final fluorescence chromophore concentrations ranging from $0.005 \%$ to $0.015 \%$ acriflavine ( $w / w$ on PLA). These fluorescently labelled PLAs were produced on ca. $50 \mathrm{~g}$ scale.

This melt mixing procedure was also applied to mix the labelled PLA with wood fibre. One extrusion run was sufficient to mix the fluorescently labelled PLA master batch, pure PLA and wood fibres with compounding also undertaken at $170^{\circ} \mathrm{C}$ for $1 \mathrm{~min}$ to minimise any fluorescence degradation. The final PLA/wood fibre contents were $95 / 5$ and $75 / 25$ on an oven dry basis.

PLA sheets / foils were formed on a hot press $\left(300 \times 300 \mathrm{~mm}^{2}\right)$ (Weverk, Sweden) using a platen temperature of $180^{\circ} \mathrm{C}$. A small amount of labelled PLA (1-5 g) was placed between two $0.8 \mathrm{~mm}$ aluminium plates covered with Teflon sheets and separated by $0.3 \mathrm{~mm}$ spacer bars. A pressure of $50 \mathrm{kN}$ was applied for ca. $45 \mathrm{~s}$ ( $<1 \mathrm{~min}$ total pressing time). The recovered PLA foils were typically 200-300 $\mu \mathrm{m}$ thickness.

\subsection{Composite Sandwich Formation and Automated Bond Evaluation System (ABES) Testing}

A modified ABES instrument from Adhesive Evaluation Systems (Corvallis, OR, USA) was used to prepare and test composite sandwiches in situ [8]. The wood veneer strips $\left(20 \times 100 \mathrm{~mm}^{2}\right)$ were mounted with a $5 \mathrm{~mm}$ overlap and a PLA foil section $\left(2.7 \times 20 \mathrm{~mm}^{2}\right)$ was positioned between the overlapped veneer strips. The press heads were then closed and composite sandwich assembly hot-pressed at either 140 or $200{ }^{\circ} \mathrm{C}$ for $20 \mathrm{~s}$ with a constant pressing force $(190 \mathrm{~N})$ for each variation. At the completion of the hot-pressing step, the press heads were rapidly cooled to $45^{\circ} \mathrm{C}$ with the press heads still closed. After achieving $45^{\circ} \mathrm{C}$ for $10 \mathrm{~s}$, the press heads were opened and the composite sandwich then tested (pulled) in tension recording the break load. At least 8 replicates were prepared and tested for each sample set. Samples for microscopy-only evaluation were prepared as above, but after cooling to $45^{\circ} \mathrm{C}$ each specimen was removed from the ABES equipment untested.

\subsection{Confocal Microscopy Analysis}

A confocal TCS SP5 microscope (Leica, Germany) was used for all assessments of PLA fluorescence, PLA/wood fibres combinations (as foils) and composite sandwich bondlines. Samples from foils or sectioning bondlines from composite sandwiches were prepared by either cutting 2-3 mm sections or microtoming 20-30 $\mu \mathrm{m}$ sections of bonded veneers, respectively. Bondline images were acquired with a $10 \times$ or $60 \times$ lens at a resolution of $1024 \times 1024$ pixels and a stepwise depth of 2-3.5 $\mu \mathrm{m}$. Excitation wavelengths were $476 \mathrm{~nm}$ and $561 \mathrm{~nm}$ (Argon laser) and fluorescence was recorded at 488-507 $\mathrm{nm}$ and $570-707 \mathrm{~nm}$. Photomultiplier gain settings were adjusted for every image to avoid overexposure. Typically, 10 images of each bondline were obtained per sample. The image stacks were projected to a single image using maximum intensity projection (Leica Application Suite Advanced Fluorescence Lite (LAS AF Lite software, Germany). Emissions in the 488-507 nm region are represented in green and emissions in the $570-707 \mathrm{~nm}$ region are represented in red in microscopy images (Figure 1). Additional, selected images are also available in Supplementary Materials. 

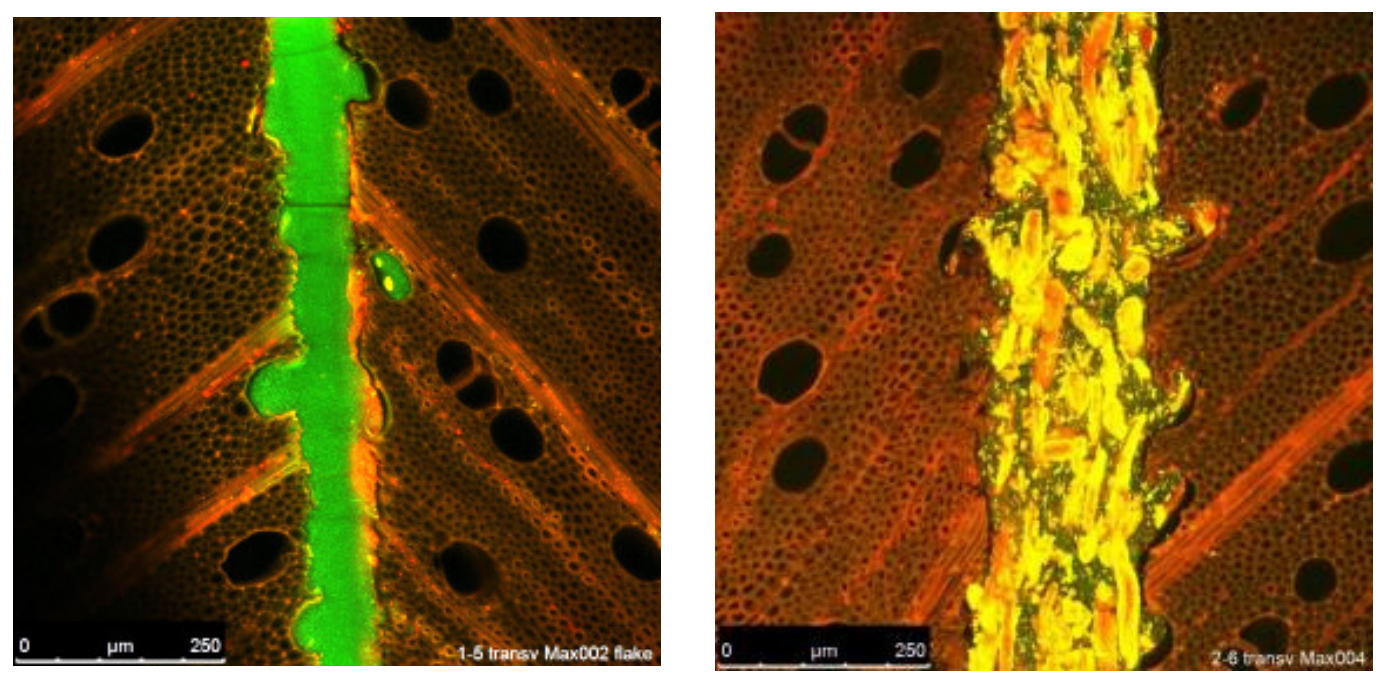

Figure 1. Representative images of bondlines formed with maple veneer and poly(lactic acid) (PLA) foil produced by microtoming a 20-30 $\mu \mathrm{m}$ section (left), and maple veneer and PLA foil containing $25 \%$ wood fibres cut as a $2-4 \mathrm{~mm}$ section from the composite (right). PLA is green and wood and wood fibre is red-yellow. The bondline thickness is defined as the distance between the two veneer faces.

Composite sandwich bondline thickness was also measured using the LAS AF Lite software. The bondline thickness was determined as the distance between the two wood veneer surfaces, perpendicular to the direction of the bondline (Figure 1, and also see Supplementary Materials). Regions where PLA was present in vesicular structures or surface defects were not included in these measurements.

\section{Results and Discussion}

\subsection{Fluorescence Chromophore Grafting to PLA}

An appropriate fluorescence label concentration for poly(lactic acid) (PLA) foils was required to achieve the quality microscopy images produced in this study. The fluorescence of labelled PLA needed to match the inherent autofluorescence intensities of wood components within the hardwood and softwood veneer sandwiches and fibres, respectively [12]. Higher acriflavine chromophore concentrations $(>0.05 \% w / w)$ have been used previously for polyester wood-plastic composites [10], but with wood veneer laminates this chromophore concentration and a lower degree of thermomechanical processing led to undesirably high PLA fluorescence intensity relative to the lignin autofluorescence [7]. This necessitated improving the acriflavine-PLA grafting via amido-functionalisation (Scheme 1) and better anticipating any thermally induced fluorophore degradation. Coupled with efficient washing [11], master batches of fluorescently labelled PLA could be readily produced at $>60{ }^{\circ} \mathrm{C}$ without significant PLA hydrolysis or polymer de-esterification and impact to PLA polymer properties. At softwood fibre loadings of $5 \% w / w$ in PLA, the wood fibres could be distinguished across a range of acriflavine loadings from 0.007 to $0.015 \%$ on PLA $(w / w$, Figure 2). To ensure sufficient distinctions between PLA and the different wood species used in this study a chromophore concentration of $0.0075 \%$ was used and facilitated by microscope photomultiplier adjustments. The lack of any discernible chromophore leaching at this loading was also evident in images such as Figures 1 and 2. Furthermore, polymer analysis indicated that the grafting, compounding, and master batching had minimal effect on fluorescently labelled PLA properties including further processing to combine with wood fibre, PLA foil production and ABES testing (Supplementary Materials). 

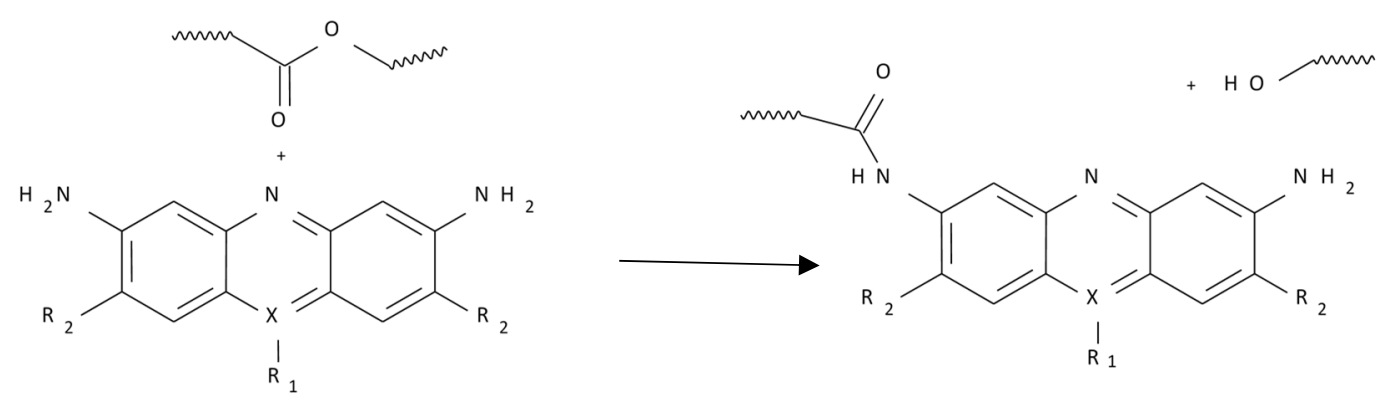

Scheme 1. Proposed modification of poly(lactic acid) polymer with acriflavine. Conditions: water/chloroform, $60^{\circ} \mathrm{C}$.
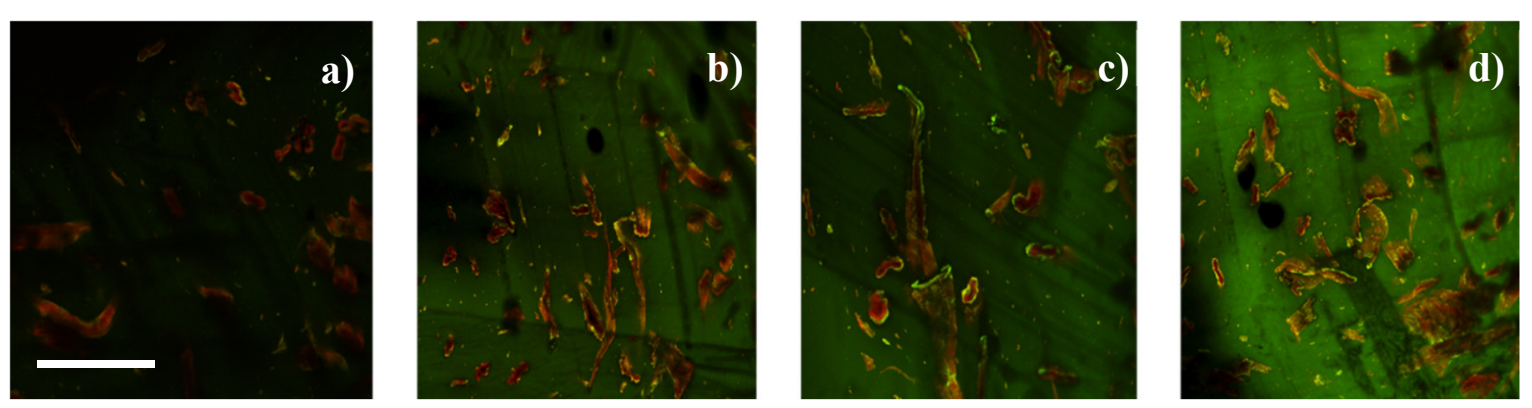

Figure 2. Confocal laser scanning microscopy images showing differing acriflavine concentrations in PLA. Labelled PLA (green) compounded with softwood medium-density fibreboard wood fibres (red):

(a) 0.005\% labelled PLA; (b) 0.0075\% labelled PLA; (c) 0.01\% labelled PLA; (d) 0.015\% labelled PLA. Scale bar is $500 \mu \mathrm{m}$.

\subsection{Composite Sandwich Formation and In Situ Testing}

Composite sandwiches were prepared using maple or spruce veneers and labelled PLA foils containing $0 \%$ to $25 \%$ wood fibre using the established ABES processing methodology [8]. Composite sandwiches were manufactured at two temperatures, 140 and $200{ }^{\circ} \mathrm{C}$, and then evaluated in situ via $\mathrm{ABES}$ tensile testing. Pressing temperature and wood fibre content both influenced the bond strength of maple veneer composites (Figure 3). With PLA only, pressing at $140{ }^{\circ} \mathrm{C}$ gave a bond strength value of $8.7 \mathrm{~N} / \mathrm{mm}^{2}$, whereas composites formed at $200{ }^{\circ} \mathrm{C}$ had significantly greater values $\left(10.4 \mathrm{~N} / \mathrm{mm}^{2}\right)$. This distinction in performance with temperature has been observed previously for a range of thermoplastic composite sandwiches [8] and was also consistent with the results obtained for semi-crystalline and amorphous grades of PLA [7]. With PLA being a relatively rigid, brittle polymer, these composite sandwiches were also evaluated with $5 \%$ and $25 \%$ wood fibre added to the PLA to understand any beneficial reinforcing effects of the fibres. An increase in strength and stiffness is typically seen in WPCs with natural fibre use [13]. Addition of 5\% wood fibre to the PLA foil did not impact the bond strength developed at either temperature. At $25 \%$ wood fibre content, bondlines formed at $140{ }^{\circ} \mathrm{C}$ have lower bond strength values $\left(6.4 \mathrm{~N} / \mathrm{mm}^{2}\right)$ compared with pure PLA. When pressed at $200{ }^{\circ} \mathrm{C}$ the $25 \%$ wood fibre content does not reduce the bondline strength $\left(9.1 \mathrm{~N} / \mathrm{mm}^{2}\right)$.

Using spruce veneer and PLA led to lower bondline performance with or without wood fibre (Figure 3). The pure PLA composites prepared at $200{ }^{\circ} \mathrm{C}$ appeared to have greater average bond strength $\left(5.7 \mathrm{~N} / \mathrm{mm}^{2}\right)$ than the composite prepared at $140{ }^{\circ} \mathrm{C}\left(4.7 \mathrm{~N} / \mathrm{mm}^{2}\right)$, but due to high testing variability, these values were not significantly different (significance level: 0.05 ). At $25 \%$ wood fibre content, the spruce sandwich composites had bond strength values of 5.2 and $3.5 \mathrm{~N} / \mathrm{mm}^{2}$ when formed at $200{ }^{\circ} \mathrm{C}$ and $140{ }^{\circ} \mathrm{C}$, respectively. Like maple, the presence of $25 \%$ wood fibre reduced the bondline strength at the lower press temperature. Pressing spruce samples at $200{ }^{\circ} \mathrm{C}$ with $25 \%$ wood fibre in PLA did not significantly change bondline performance, consistent with the observation for maple. 


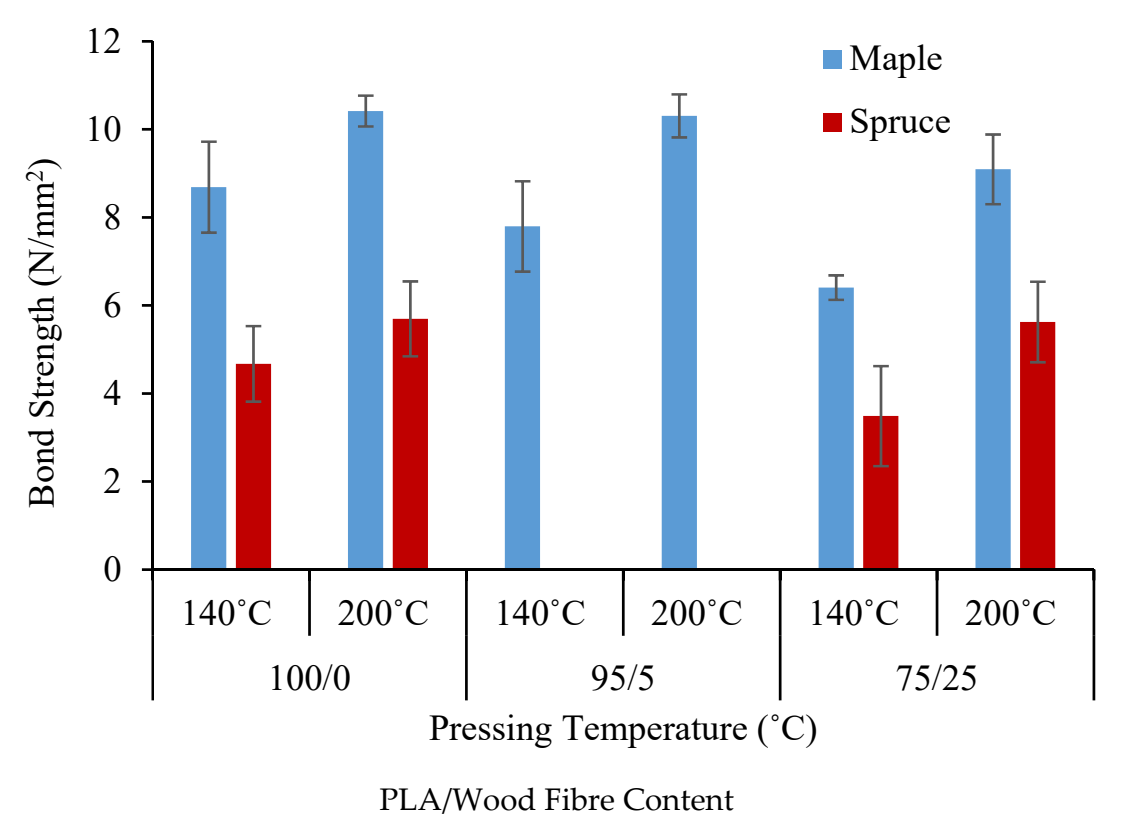

Figure 3. Comparisons of average tensile bond strength values for composites produced with maple and spruce veneers with $0 \%$ to $25 \%$ wood fibre content in PLA foils. Error bars are 0.05 significance level.

\subsection{Fluorescence Microscopy}

The bondlines formed with PLA and maple or spruce veneers were visualised by confocal microscopy (CLSM, Figures 1 and 4-7). Fluorescently labelling the PLA produced clear distinctions of this polymer from both wood species as well as any wood fibres additionally contained within each bondline (Figures 1 and 4, with additional images available in Supplementary Materials). The microscopy cross sections of bondlines profile PLA mobility and migration into vesicular structures of the wood, similar to more traditional adhesive bondlines formed in plywood [9,14]. Examples of bondlines contrasting pure PLA and PLA containing 25\% softwood fibres are shown in Figure 1. In addition to changes in bondline thickness between veneer surfaces, images contain other pertinent information such as PLA migration away from the bondline, wood fibre distributions and how these fibres were deposited within the bondline in terms of anisotropy and alignment of fibres in the $\mathrm{X}-\mathrm{Y}$ plane of the bondline.

\subsection{Maple}

Shown in Figure 4 are qualitative comparisons of bondlines formed with pure PLA and maple veneer at $140{ }^{\circ} \mathrm{C}$ and $200^{\circ} \mathrm{C}$. On pressing at $140{ }^{\circ} \mathrm{C}$, it was evident that the PLA filled the relatively uneven veneer surfaces and was able to flow into the maple vesicular structure. This indicates that PLA possesses some degree of mobility promoted by this pressing temperature and pressure used. At $200^{\circ} \mathrm{C}$, PLA was also observed to migrate into the maple vessels with images showing PLA contained within the vesicular structure. At higher magnification (Figure 4c), which details a relatively rough veneer surface, PLA was observed to have migrated through a range of pores, including vessels, ray cells and within fibre lumens. Moreover, this PLA movement and penetration was via pits and vessels within the wood ultrastructure and appears not to enter fibre cell walls. This flow and behaviour is distinct from those of adhesives and resins which typically exhibit resin migration into cell walls [12,15]. Additionally, across the images (Figures 1 and 4), it was evident that PLA migrated further from the bondline, providing a greater interface with the wood for those samples pressed at $200{ }^{\circ} \mathrm{C}$ than for those at the lower temperature. 


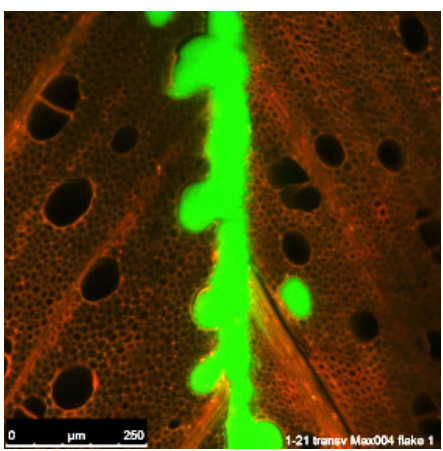

(a)

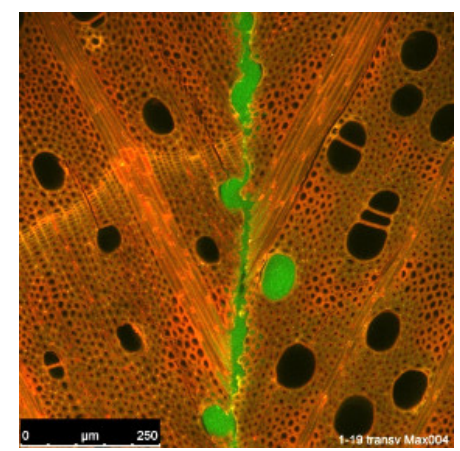

(b)

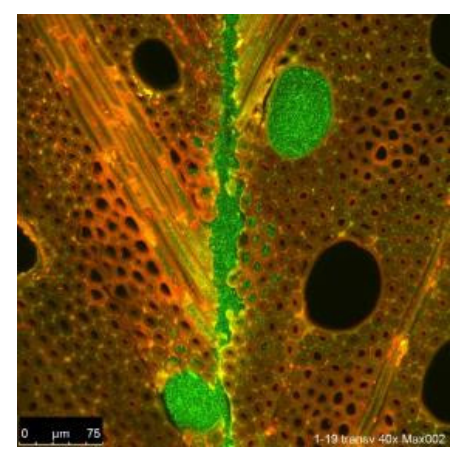

(c)

Figure 4. Representative confocal microscopy (CLSM) images of maple-PLA composite sandwiches formed at (a) $140{ }^{\circ} \mathrm{C}$, transverse view; (b) $200{ }^{\circ} \mathrm{C}$, transverse view; and (c) $200{ }^{\circ} \mathrm{C}$, transverse view at higher magnification.

In addition to visual differences in PLA flow and mobility behaviours, the thickness of maple bondlines pressed at $140{ }^{\circ} \mathrm{C}$ typically ranged between $50 \mu \mathrm{m}$ and $100 \mu \mathrm{m}$ (Figure 5). This variation in pure PLA bondline thicknesses is evident in Figure 4a. Visually, this thickness was relatively greater than the width of a maple vessel, as observed in Figure 3. Compared to bondlines formed at $140{ }^{\circ} \mathrm{C}$, those formed at $200{ }^{\circ} \mathrm{C}$ (Figure $4 \mathrm{~b}$ ) were relatively thinner $(10-30 \mu \mathrm{m})$ with this attributable to pressing above the PLA melt temperature. Moreover, this relatively thin bondline was consistent with the observed greater PLA migration into the vesicular structure away from the bondline.

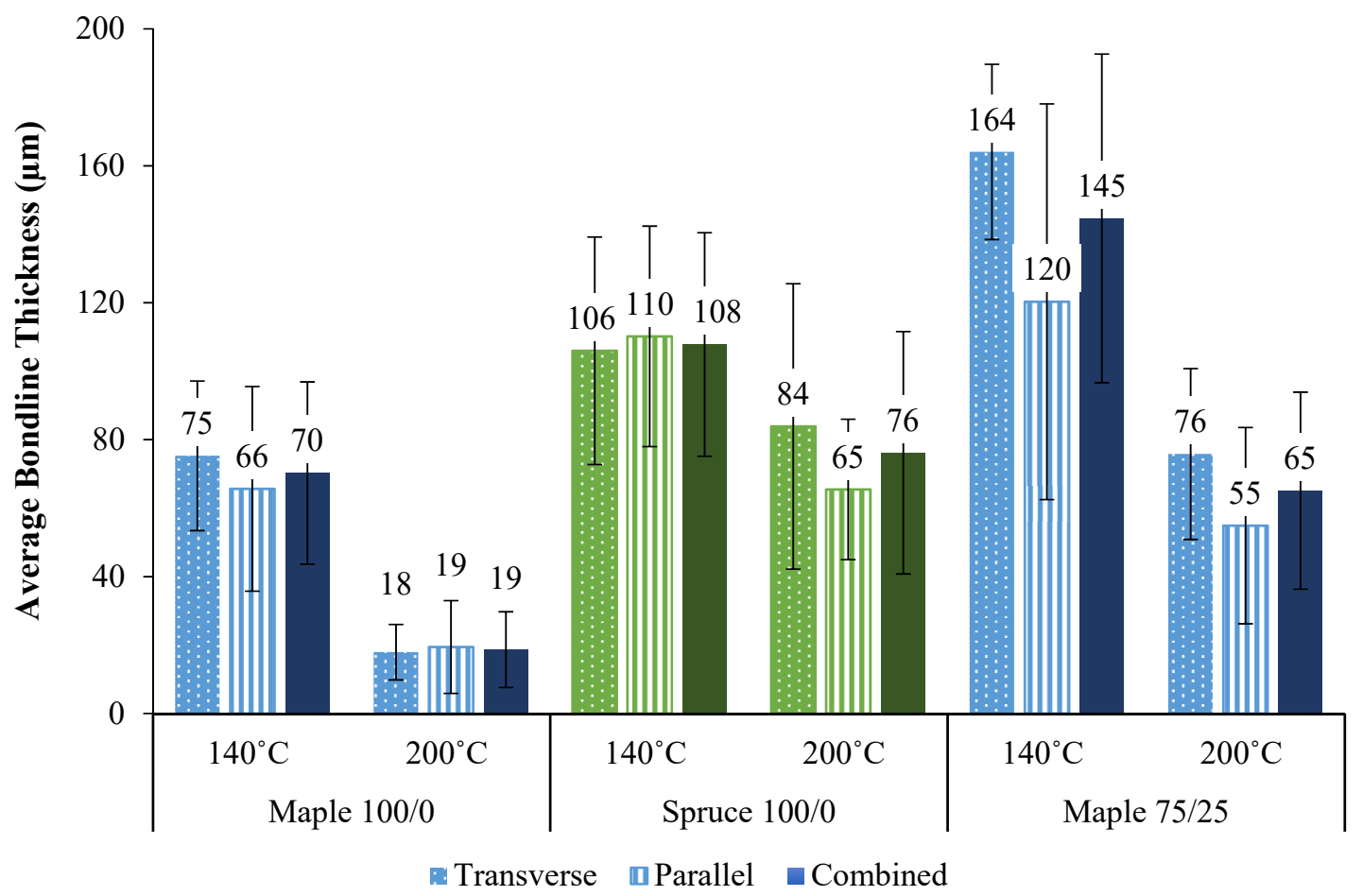

Figure 5. Comparisons of average bondline thickness values for composites produced with maple and spruce veneers with $0 \%$ to $25 \%$ wood fibre content in PLA foils. Error bars are 0.05 significance level.

For those composite sandwiches formed with PLA containing wood fibres, the images distinguish these softwood fibres from the maple veneer (Figures 1 and 6). For samples pressed at $140{ }^{\circ} \mathrm{C}$ (Figure 6), wood fibres appear evenly distributed within the bondline formed between the veneer surfaces. In both transverse and parallel orientations (Figure 6) the expected alignment of fibres parallel with the direction of the bondline is evident. However, this appears to be associated with a 
high degree of fibre anisotropy within the bondline which was likely induced during both pressing as a foil sheet and then as the composite sandwich. The images also show significant fibre overlaps which appear not to allow veneer surfaces to compress together along the bondline as well as the deposition of fibre debris within the entrances to vessels. It is evident from the images that PLA was still able to migrate into and along open vessels adjacent to the bondline, as observed with pure PLA bondlines (Figures 1 and 4). At higher magnification (Figure 6), wood fines (very small wood fibre particles) within the PLA were observed to have passed into maple vessels during pressing. From these images it is difficult to estimate whether the deposition of this fine material acts to influence PLA mobility away from the bondline. As above, the poor dispersion of wood fibres, together with their overlaps, also inhibits closer contact between veneer surfaces in areas along the bondline, which may be considered a contributor to the large variation observed in bondline thicknesses which range from 50 to $230 \mu \mathrm{m}$ (Figure 5).

Forming composite sandwiches with PLA/25\% wood fibre at higher temperature (Figure $6 \mathrm{~b}$ ) led to a decrease in bondline thickness, as found when using pure PLA foil (Figure 4). Additionally, PLA migrated further into the vessels, as was seen with maple/PLA pressed at $200{ }^{\circ} \mathrm{C}$. As above with the $140{ }^{\circ} \mathrm{C}$ sample, fibres align parallel to the bondline. The images show greater PLA migration into the veneer substrate and regions where wood fibres were unevenly spaced and clustered, with some PLA regions dominated by wood fibre fines. At higher magnification (Figure 4c), there were instances where wood fibres may have restricted PLA from entering adjacent veneer wood cell lumens. Moreover, with transversal views of the bondline (Figure 6c), there were relatively fewer areas where PLA was observed within lumens near the bondline compared to with pure PLA use at $200{ }^{\circ} \mathrm{C}$. From these images (Figure 6b,c, Supplementary Materials) it is evident that there was a wide range of bondline thicknesses, but these generally appeared thinner (30-100 $\mu \mathrm{m}$, Figure 5) than those of the corresponding PLA/ $25 \%$ wood fibre sample pressed at $140{ }^{\circ} \mathrm{C}$ (Figure 6a).

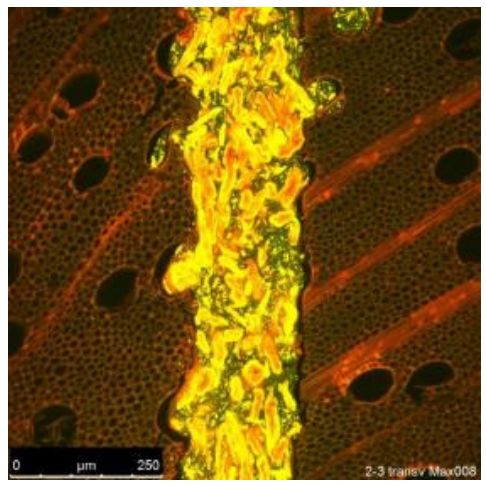

(a)

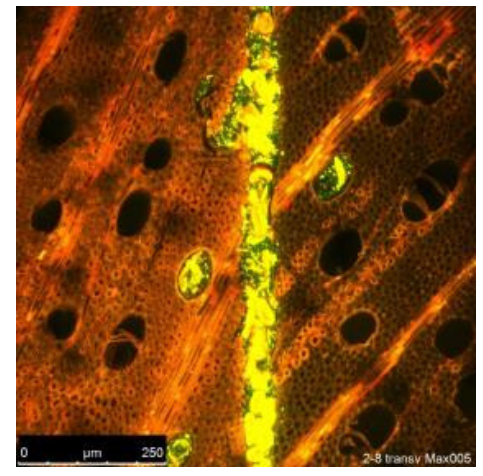

(b)

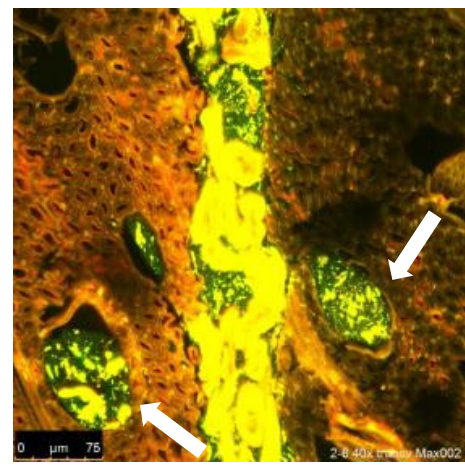

(c)

Figure 6. Representative CLSM images of maple-PLA/ $25 \%$ wood fibre composite sandwiches formed at (a) $140{ }^{\circ} \mathrm{C}$, transverse view; (b) $200{ }^{\circ} \mathrm{C}$, transverse view; and (c) $200{ }^{\circ} \mathrm{C}$, transverse view at higher magnification with arrows showing deposition of wood fines.

\subsection{Spruce}

Imaging composite sandwiches formed with spruce veneer provided greater visual contrast between this softwood lignin autofluorescence and the acriflavine chromophore compared to those with the maple veneer (Figure 6). In addition to exhibiting earlywood and latewood cell deposition, composite bondlines formed with spruce veneer and pure PLA at $140{ }^{\circ} \mathrm{C}$ (Figure 7a) appeared thicker $(65-140 \mu \mathrm{m})$ than those of composites formed with maple (Figure 4a). Microscopy also revealed evidence of PLA flow into exposed spruce lumens adjacent to the bondline, with higher magnification (Figure $7 \mathrm{~b}$ ) revealing PLA migration up to ca. $100 \mu \mathrm{m}$ away from the bondline.

Spruce veneer sandwiches pressed at $200{ }^{\circ} \mathrm{C}$ (Figure 7c) generally had thinner bondlines with greater PLA migration away from bondlines than found in those pressed at $140{ }^{\circ} \mathrm{C}$ (Figures 5 and $7 \mathrm{a}$ ). 
Also evident in the transverse views are variations in bondline thickness typical of this sample. Bondline thicknesses ranged between 40 and $130 \mu \mathrm{m}$ across CLSM images. A greater rate of PLA migration away from bondlines, up to four cells deep, was evident at $200^{\circ} \mathrm{C}$ with this migration also extending into ray cells. Although spruce samples were produced with PLA containing wood fibres (Figure 2), only some were imaged (see Supplementary Materials), and these were not extensively analysed as above for maple samples.

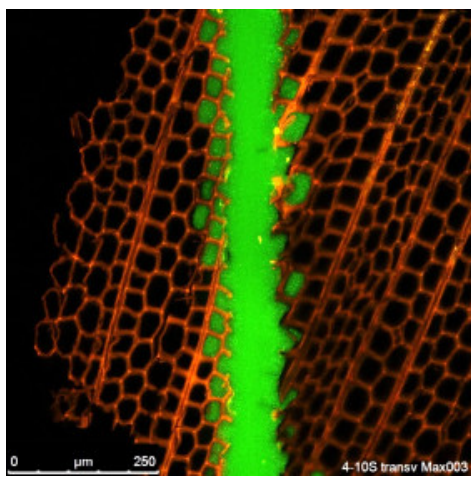

(a)

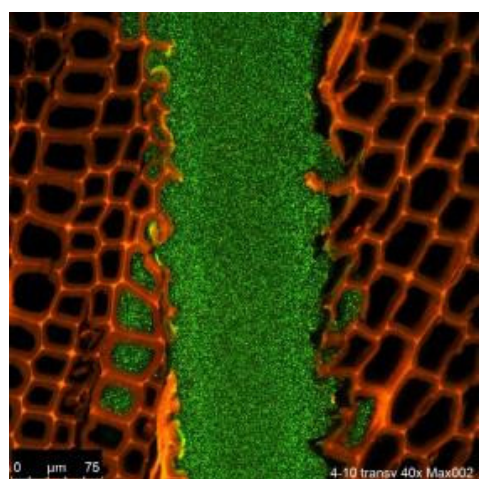

(b)

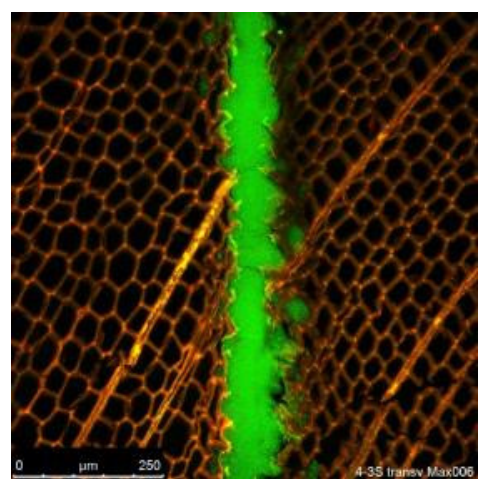

(c)

Figure 7. Representative CLSM images of spruce-PLA composite sandwiches formed at (a) $140{ }^{\circ} \mathrm{C}$, transverse view; (b) $140{ }^{\circ} \mathrm{C}$, transverse view at higher magnification; and (c) $200^{\circ} \mathrm{C}$, transverse view.

\subsection{Bondline Thickness Quantification}

A summary of average PLA bondline thickness, defined as the distance between veneer surfaces (Supplementary Materials), is provided in Figure 5 and includes bondlines evaluated in both transverse and parallel bondline orientations. Along with the qualitative observations above, bondline measurements undertaken for all images revealed that those samples pressed at $200{ }^{\circ} \mathrm{C}$ had relatively thinner bondlines than the corresponding samples pressed at lower temperature. Although the maple-pure PLA sample pressed at $200^{\circ} \mathrm{C}$ had the thinnest average bondline thickness $(19 \mu \mathrm{m})$ of all samples, there was high variability in the thickness values. Bondline thicknesses were 3 times greater for $140{ }^{\circ} \mathrm{C}$ samples $(70 \mu \mathrm{m})$ than for those formed at $200^{\circ} \mathrm{C}$. Furthermore, despite the high variability visually evident in images, these average bondline thickness values were statistically different between the two pressing temperatures. Imaging in both transverse and parallel views also revealed a relative consistency in these bondline measurements. As observed with qualitative observations, addition of wood fibre to PLA led to bondlines which were 3 times thicker $(76 \mu \mathrm{m})$ than pure PLA bondlines when pressed at $200{ }^{\circ} \mathrm{C}$. In the case of pressing at $140{ }^{\circ} \mathrm{C}$, the presence of wood fibre in PLA produced a $50 \%$ greater thickness $(108 \mu \mathrm{m})$ than pure PLA. However, evident in these quantitative measurements was the substantial variation in bondline thicknesses observed in the qualitative image assessments above (Figures 1 and 6). With spruce veneer, image analysis revealed relatively thicker PLA bondlines than those with maple at both pressing temperatures. While these averaged $76 \mu \mathrm{m}$ and $108 \mu \mathrm{m}$ for $200{ }^{\circ} \mathrm{C}$ and $140{ }^{\circ} \mathrm{C}$, respectively, these values were not statistically significant, indicative of the high variability across the bondlines surveyed. Moreover, these average thicknesses were more comparable to those observed with maple and PLA with $25 \%$ wood fibre.

\section{Discussion}

Across the microscopy images it was evident that PLA polymer flow and mobility at temperature dictated the PLA bondline thicknesses observed previously in composite sandwich formation [7]. The initial PLA foil thickness (ca. $300 \mu \mathrm{m}$ ) did not define the bondline thickness or the extent of migration into the wood substrate as PLA was additionally squeezed out on pressing; this can also occur when gluing wood with traditional adhesives [16]. While flow of PLA into wood vesicular structures was generally observed (Figures 1-7), there was no defined PLA infiltration into wood 
cell walls of the veneer surface or individual softwood fibres. This is distinct from liquid wood adhesive behaviours where cell wall infiltration is commonly observed [12,14]. This suggests that the greater molecular weight of PLA [14], together with polymer hydrophobicity [9] and/or high viscosity, may restrict PLA mobility into the wood cell wall compared to that of the water-soluble condensation polymers of typical wood adhesive systems [12,14]. Moreover with liquid wood adhesives, adhesive flow can be parameterised to measure adhesive penetration depth from bondlines. However, this can be difficult given the randomness of the wood structure, particularly in hardwoods [14], which was also apparent across the various bondline images in this study. Nonetheless, both the qualitative observations and the quantitative information obtained in this study can be combined to describe how bondline strength is developed during composite sandwich formation and the effect of wood fibre inclusion with PLA.

On pressing composite sandwiches at $200^{\circ} \mathrm{C}$, the PLA has a lower viscosity more comparable to that of liquid adhesives [7]; this contributes to greater PLA mobility into the wood and correspondingly thinner bondlines due to the extent of this ingress (Figures 4 and 7). This presence of PLA in the wood matrix provides a greater interface between the PLA polymer and wood matrix, contributing to better interfacial adhesion as well as the benefit of physical interlocking of PLA within the wood ultrastructure to reinforce the wood-PLA interface. At the same time, the thickness of bondlines being generally less than $100 \mu \mathrm{m}$ may challenge liquid adhesives' requirements for thicker $(100-800 \mu \mathrm{m})$, gap-filling bondlines to achieve good adhesion between wood surfaces [16]. In contrast, at $140{ }^{\circ} \mathrm{C}$, greater PLA viscosity reduces flow and ingress into the wood matrix and was associated with the retention of a thicker bondline. In assessing the tensile strength of bondlines, the relative thickness of the PLA matrix may impact the stress transfer across PLA bondlines, particularly given that PLA is a hard, rigid polymer below its glass transition when tested $[17,18]$. However, with tensile testing, a thinner PLA bond appeared able to transfer stress and, in combination with greater interfacial adhesion and mechanical interlocking, provided higher performance of composites formed at $200{ }^{\circ} \mathrm{C}$.

With wood fibre incorporation, bondline thickness variously increased by some $100 \%$ at $140{ }^{\circ} \mathrm{C}$ and ca. $240 \%$ at $200{ }^{\circ} \mathrm{C}$ pressing temperature. The variable strength of these composite sandwiches suggests that the deposition of wood fibres within the $\mathrm{X}-\mathrm{Y}$ plane of testing did not readily act to transfer stress across the bondline as expected for fibre-reinforced plastics [6]. Instead, wood fibre alignment and overlap in the heterogeneous bondline contributed to greater bondline thickness and potentially a lower degree of PLA ingress. A resulting impact was lower strength of the maple-PLA composite sample with $25 \%$ wood fibre pressed at $140{ }^{\circ} \mathrm{C}$. However, thinner bondlines and sufficient PLA ingress were evident for the corresponding $200{ }^{\circ} \mathrm{C} / 25 \%$ wood fibre sample which had comparable performance to pure PLA (Figure 2) or other polymers [8]. For spruce samples, the presence of wood fibre in PLA does not appear to significantly impact composite performance.

With spruce veneer, the contrasting cellular structures of spruce and maple led to distinctions in bondline thickness, with spruce-PLA bondlines being generally thicker (Figure 5); this was attributable to lower PLA mobility and ingress away from the bondline. A greater bondline thickness together with lower PLA ingress arguably contributed to reduced interfacial adhesion, resulting in lower bond strength in spruce samples than in those of maple. However, along with surface morphology, differences in wood chemistry and surface polarity may also contribute to this weaker PLA-spruce wood interface. The effect of polymer polarity has previously been demonstrated by significantly lower composite sandwich bond strengths for polyethylene or polypropylene polymer foils which have relatively similar melting points and melt flow to PLA [8]. Any impact of wood chemistry and polymer surface polarity may also extend to using softwood wood fibre in PLA, which potentially may have impacted interfacial adhesion, reinforcement and stress transfer within the PLA matrix. However, as above, wood fibre inclusion with PLA did not significantly impact spruce composite performance. Furthermore, polymer crystallinity around wood-polymer interfaces and within the plastic/polymer matrix will also impact performance, so must also be considered in the context of interfacial properties $[6,17,18]$. In related adhesion studies, nano- and molecular-scale interactions have 
also been found to be important [14], and these will also need to be considered in sandwich composite formation and performance. Further studies will be required to understand these complexities across differing scales in the formation and performance of plastic-wood interfaces.

Overall, we find bond strength increases with temperature and, through the promotion of PLA flow into the wood vesicular structure, provides improved mechanical adhesion and reinforcement of bondlines. At the same time, any need to maintain a minimum bondline thickness may not be a requirement as wood-wood contacts increase due to a lack of gap filling [16]. The addition of wood fibres may present a way to achieve both greater polymer flow at higher temperature and, acting as a "spacer", the impediment of excessive flow into the wood vesicular structure, which may ensure a sufficient adhesive layer between the veneer substrates. Nonetheless, composite strength requirements will be dependent on applications, and study findings suggest that if higher strength is needed, higher processing temperatures should be employed.

\section{Concluding Remarks}

A microscopy methodology was developed for qualitative and quantitative assessments of bondlines formed in composite sandwich manufacture with wood veneer and PLA. The use of ca. 0.0075\% fluorescent chromophore in PLA matched to the lignin autofluorescence of veneer sandwiches allowed the visualisation of PLA flow and ingress at the wood cell level. The use of higher sandwich formation temperatures promoted PLA mobility further into the wood ultrastructure, acting as anchor points for the reinforcement of bondlines. This was demonstrated with both maple and spruce composite sandwiches formed at 140 and $200{ }^{\circ} \mathrm{C}$ with the higher processing temperature resulting in greater composite bond strength. The study results reiterated that relatively higher bond strengths can be achieved by bonding wood veneer with PLA. It is the PLA/wood interface which promotes this bond strength and associated stress transfer across the PLA matrix. Maple veneer revealed greater PLA ingress and bond strength compared with spruce veneer use. Overall, the study findings and, particularly, the impact of processing temperature on laminate strength and adhesion will have broad applications across the manufacture of veneer overlays, laminate composites and WPCs using wood substrates, particles or fibre with PLA.

Supplementary Materials: The following are available online at http:/ /www.mdpi.com/2079-6439/7/2/15/s1.

Author Contributions: These include conceptualization, W.G., A.K., J.L. and M.G.; formal analysis, W.G. and M.G., A.K. and J.L.; investigation, W.G., V.G., K.R., M.G.; writing-original draft preparation, W.G.; writing-review and editing, W.G., A.K., J.L. and M.G.; supervision, M.G. and W.G.; funding acquisition, W.G., A.K., J.L. and M.G.

Funding: "This research was funded by the New Zealand-Germany Science and Technology Programme administered by the New Zealand Royal Society and the Bundesministerium für Landwirtschaft und Ernährung.

Acknowledgments: The authors are grateful to the following organisations for assistance with funding for the New Zealand-Germany Science and Technology Programme. This was contributed to by the New Zealand Royal Society and Catalyst Seed funding [FRG-FRI1402] and the Bundesministerium für Landwirtschaft und Ernährung (Federal Ministry of Food and Agriculture) [02/14-15-NZL], together with resourcing provided by the Thünen Institute of Wood Research, Scion and the University of Hamburg. K.R. was a recipient of a University of Waikato summer studentship scholarship and, along with V.G., studentship placements also supported and resourced by Scion.

Conflicts of Interest: The authors declare no conflict of interest.

\section{References}

1. Mertens, O.; Gurr, J.; Krause, A. The utilization of thermomechanical pulp fibers in WPC: A review. J. Appl. Polym. Sci. 2017, 134, 45161. [CrossRef]

2. Kilyosov, A.A. Wood Plastic Composites; Wiley \& Sons: Hoboken, NJ, USA, 2007; p. 726.

3. Chen, Y.; Geever, L.M.; Killion, J.A.; Lyons, J.G.; Higginbotham, C.L.; Devine, D.M. Review of multifarious applications of poly (lactic acid). Polym.-Plast. Technol. Eng. 2016, 55, 1057-1075. [CrossRef] 
4. Nagarajan, V.; Mohanty, A.K.; Misra, M. Perspective on polylactic acid (PLA) based sustainable materials for durable applications: Focus on toughness and heat resistance. ACS Sustain. Chem. Eng. 2016, 4, 2899-2916. [CrossRef]

5. Garlotta, D. A literature review of poly(lactic acid). J. Polym. Environ. 2001, 9, 63-84. [CrossRef]

6. Peltola, H.; Pääkkönen, E.; Jetsu, P.; Heinemann, S. Wood based PLA and PP composites: Effect of fibre type and matrix polymer on fibre morphology, dispersion and composite properties. Compos. Part A Appl. Sci. Manuf. 2014, 61, 13-22. [CrossRef]

7. Luedtke, J.; Gaugler, M.; Grigsby, W.J.; Krause, A. Understanding the development of interfacial bonding within PLA/wood-based thermoplastic sandwich composites. Ind. Crop. Prod. 2019, 127, 129-134. [CrossRef]

8. Gaugler, M.; Luedtke, J.; Grigsby, W.J.; Krause, A. A new methodology for rapidly assessing interfacial bonding within fibre-reinforced thermoplastic composites. Int. J. Adhes. Adhes. 2019, 89, 66-71. [CrossRef]

9. Paris, J.L.; Kamke, F.A. Quantitative wood-adhesive penetration with X-ray computed tomography. Int. J. Adhes. Adhes. 2015, 61, 71-80. [CrossRef]

10. Grigsby, W.J.; Thumm, A.; Klepser, H. Assessing interfacial behaviours of natural fibre-plastic composites by fluorescent microscopy. In Proceedings of the 8th International Conference on Woodfiber-Plastic Composites, Madison, WI, USA, 19-13 May 2005.

11. Can, H.K.; Karakus, G.; Tuzcu, N. Synthesis, characterization and in vitro antibacterial assessments of a novel modified poly[maleic anhydride-alt-acrylic acid]/acriflavine conjugate. Polym. Bull. 2014, 71, 2903-2921. [CrossRef]

12. Grigsby, W.J.; Thumm, A. Resin and wax distribution and mobility during medium density fibreboard manufacture. Eur. J. Wood Wood Prod. 2012, 70, 337-348. [CrossRef]

13. Faruk, O.; Bledzki, A.K.; Fink, H.P.; Sain, M. Progress report on natural fiber reinforced composites. Macromol. Mater. Eng. 2014, 299, 9-26. [CrossRef]

14. Jakes, J.E.; Frihart, C.R.; Hunt, C.G.; Yelle, D.J.; Plaza, N.Z.; Lorenz, L.; Grigsby, W.; Ching, D.J.; Kamke, F.; Gleber, S.C.; et al. X-ray methods to observe and quantify adhesive penetration into wood. J. Mater. Sci. 2019, 54, 705-718. [CrossRef]

15. Jakes, J.E.; Hunt, C.G.; Yelle, D.J.; Lorenz, L.; Hirth, K.; Gleber, S.C.; Vogt, S.; Grigsby, W.; Frihart, C.R. Synchrotron-based x-ray fluorescence microscopy in conjunction with nanoindentation to study molecular-scale interactions of phenol-formaldehyde in wood cell walls. ACS Appl. Mater. Interfaces 2015, 7, 6584-6589. [CrossRef] [PubMed]

16. Marra, A.A. Technology of Wood Bonding: Principles in Practice; Van Nostrand Reinhold: New York, NY, USA, 1992.

17. Filgueira, D.; Holmen, S.; Melbø, J.K.; Moldes, D.; Echtermeyer, A.T.; Chinga-Carrasco, G. Enzymatic-assisted modification of thermomechanical pulp fibers to improve the interfacial adhesion with poly(lactic acid) for 3D printing. ACS Sustain. Chem. Eng. 2017, 5, 9338-9346. [CrossRef]

18. Mukherjee, T.; Tobin, M.J.; Puskar, L.; Sani, M.A.; Kao, N.; Gupta, R.K.; Pannirselvam, M.; Quazi, N.; Bhattacharya, S. Chemically imaging the interaction of acetylated nanocrystalline cellulose (NCC) with a polylactic acid (PLA) polymer matrix. Cellulose 2017, 24, 1717-1729. [CrossRef]

(C) 2019 by the authors. Licensee MDPI, Basel, Switzerland. This article is an open access article distributed under the terms and conditions of the Creative Commons Attribution (CC BY) license (http://creativecommons.org/licenses/by/4.0/). 